\title{
The Machining Process Planning of the Governor Speed Control Lever
}

\section{Dan Wang} Department of Mechanical Engineering, Dalian Vocational \& Technical College, Dalian, 116037,
China

wangdan11501@126.com

Keywords: The governor speed control lever, machining process planning, design

\begin{abstract}
With the rapid development of the machining industry, the machining process planning in machinery manufacturing occupies an important position affecting the machining quality. The governor speed control lever is one of the important parts of diesel engine governor. In this paper, we study on the difficulties and the concerned issues of the machining process planning of the governor speed control lever, combining with the actual machining process planning and the present situation of the special fixture, determine the typical parts of a typical process route, and provide theoretical reference for the establishment of procedures for the actual production parts processing process, which can improve the efficiency cost savings.
\end{abstract}

\section{Introduction}

Manufacturing is an industry to making the machine parts and products with specialized operating function, which can be used directly in the process of people's life and production. It is indispensable and plays an important role to people's life [1]. In recent years, the manufacturing industry in our country has been rapid development [2]. The governor speed control lever of diesel engine is belonging to the diesel engine governor parts, including a central fixed tube, a governor speed fork, the casting lever body and two holes with the ball head inside closely. The ball after quenching can be durable and wearable, which saves diesel engine maintenance costs. While the ball worn, which might be replaced by a new ball. Do not need the entire speed lever to be scrapped. The simple and less process do not need special ball grinding machine and heat treatment equipment. In this paper a detailed description of the mechanical processing and special fixture design of the speed control lever will be displayed.

\section{The Machining Process Planning Design of the Governor Speed Control Lever}

The Technology Analysis. The main function of the governor speed control lever is used to connect with the governor. The processing requirements of the side of the governor speed control lever are low because of the rod parts. Meanwhile, it is very convenient to process after the side have been directly forged out. On the other side, it is difficult to ensure the parallelism and perpendicularity of the holes at the same time. The processing accuracy of the lower hole is also relatively high. It is especially difficult to process the higher degree of roughness of the $\varphi 13 \mathrm{~mm}$ hole, as shown in Figure 1.

The location requirements between the surface to be machined and the processing surface of the governor speed control lever is described in the following.

(1) The roughness of the though-hole $\phi 12 \mathrm{H} 7$ is 3.2 , which is the bases A for processing other holes.

(2) The roughness of the left and right face is 12.5 , and the symmetry of the through-hole $\phi 12 \mathrm{H} 7$ is 0.5 .

(3) The roughness of the hole $\phi 6 \mathrm{H} 9$ is 1.6 , which is the bases $\mathrm{B}$ for processing other holes. The perpendicularity of the through-hole $\phi 12 \mathrm{H} 7$ is 0.1 .

(4) The roughness of the double-hole $\phi 6 \mathrm{H} 9$ is 1.6 , and the parallelism of $\phi 6 \mathrm{H} 9$ is 0.05 , the perpendicularity of the $\phi 12 \mathrm{H} 7$ is 0.05 . 
According to the economic accuracy of each processing method and the accuracy of the position of the general machine, the surfaces of the parts are not difficult to process, and the technical requirements of the surface of the use of conventional processing technology can be guaranteed.
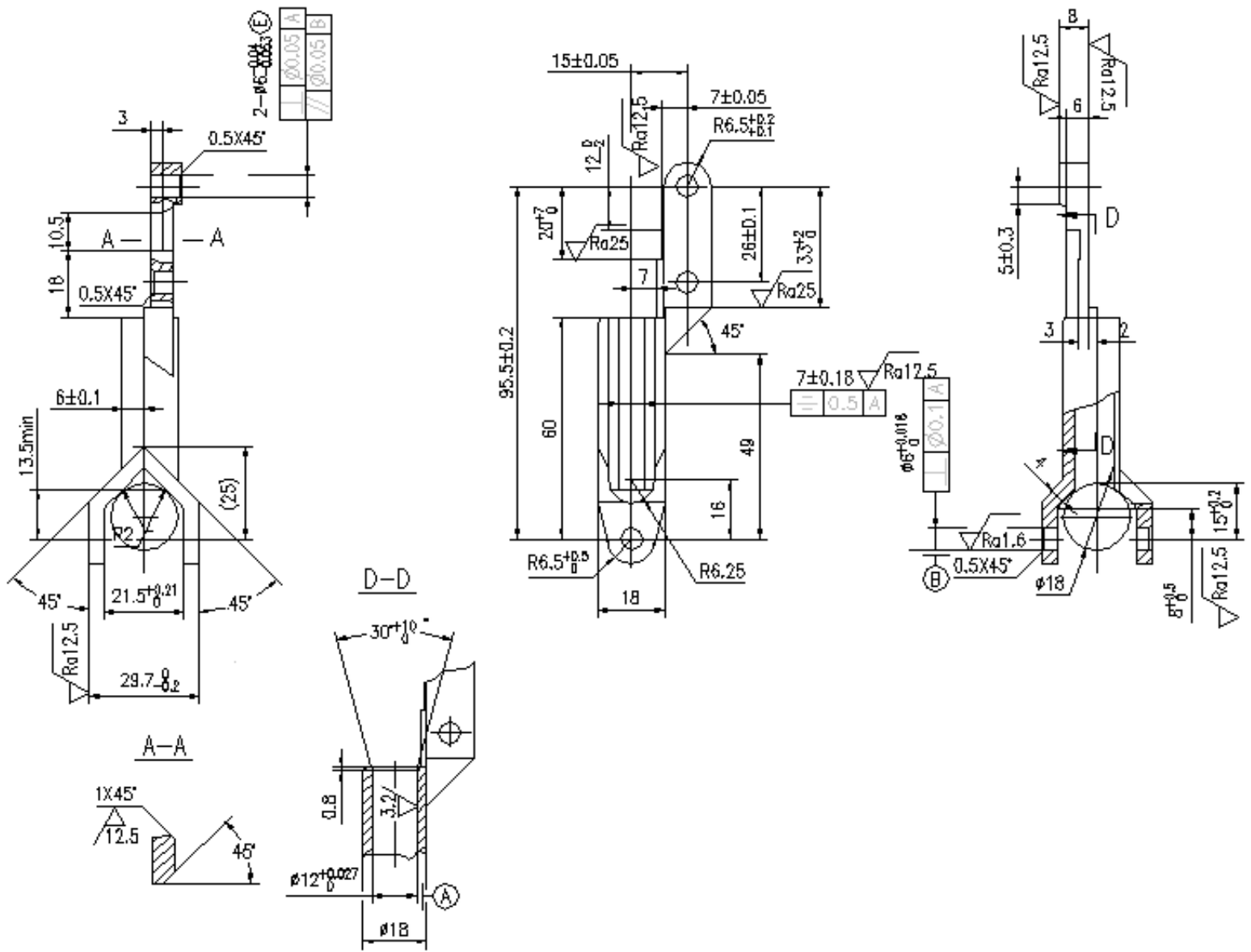

Fig.1 The drawing of the governor speed control lever

The Determination of Blank. Many papers have summarized various traditional approaches to determine the work-blank [3]. It is necessary for processing request proposed which according to the detail drawing. The definite semi-finished materials manufacture form and the size determination. The material of the governor speed control lever parts is 30 steel, whose structure is relatively simple, and the production type is a medium quantity batch production. In order to make the parts have better mechanical properties and to ensure reliable parts, so the blank with forging forming will be used, which can increase productivity and ensure processing accuracy. By checking many mechanical manuals, the unilateral allowance is $1.5-2.0 \mathrm{~mm}$ in the thickness and horizontal direction, which is according to the quality of forgings, parts surface roughness, and the shape complex coefficient. The unilateral allowance of the forging hole is $2.0 \mathrm{~mm}$ on the single side. The size of the blank is simply the size of the part added to the margin value, shown in the following table.

Table 1 The parameter of the bland

\begin{tabular}{c|c}
\hline \multirow{2}{*}{ The fillet radius } & The round radius: $r=2.5 \mathrm{~mm}$ \\
\cline { 2 - 2 } The draft angle & $\begin{array}{c}5^{\circ} \sim 10^{\circ} \\
\text { The center plane of the thin rod part is the } \\
\text { parting plane and the parting line is straight. }\end{array}$ \\
\hline The parting face position & Normalizing \\
\hline The heat treatment mode & No
\end{tabular}

The Process Route Drafting. The Choice of Locating Datum. In constituting the technical regulations for machining apart, it's crucial to choose a reasonable locating criterion [4]. 
The Selection of Rough Datum. On one hand, select the principle of the relevant reference. It is mean that, when the part has an unprocessed surface, these rough surfaces shall be used as rough reference. But if the part has a number of unprocessed surfaces, we should select a surface of the machined surface with a relatively high relative position as the rough datum. On the other hand, choose the reliable surface is the thick datum. Simultaneously, the thick datum cannot duplicate uses. In this paper, the basic choice is to consider the side of the parts as the main positioning rough basis.

The Selection of Fine Datum. First of all, it must conform to the datum superposition principle, chooses the design datum or the assembly datum as far as possible takes the localization datum. Meanwhile, it is consider to ensure the parts of the processing accuracy and clamping accurate and convenient, which should be based on the "benchmark coincidence" principle and the "benchmark unification" principle. In this paper, we select the $\phi 12 \mathrm{H} 7$ hole as the finish datum.

The Choice of Processing Method. In recent years, with the rapid development of machine manufacturing, many machining ways are well developed and used [5]. The main working surface of the governor speed control lever parts allows the end face, the outer circle and the holes. Refer to the Mechanical Manufacturing Process Design Manual, the specific processing method is proposed as follows:

(1) For the left-hand-side and right-hand-side surfaces, the cylindrical surface, the transverse convex platform face, and the cylindrical groove, the tolerance level is IT12, and the surface roughness is 12.5. The processing method of them is rough milling.

(2) For the $\phi 12 \mathrm{H} 7$ hole, the tolerance level is IT7, and the surface roughness is 3.2. The processing method of them is drill and hinge.

(3) For the $\phi 6 \mathrm{H} 9$ and double $\phi 6 \mathrm{H} 9$ holes, the tolerance level is IT9, and the surface roughness is 1.6.The processing method of them is drill, rough reaming and finish reaming.

The Manufacturing Procedure and the Processing Equipment Selection. The process route refers to a technique for describing the sequence of operations in the manufacturing process of the machine, which is a sequence of a plurality of processes and is a series of actions carried out in order to accomplish the object creation target [6]. It can design the entire process to fully grasp, and it is an important method for the implementation of machinery manufacturing quota management [7]. The basic starting point for the development of a route should ensure that the final quality of the part is guaranteed [8].

As a guidance document of the mechanical processing for the operator, the manufacturing procedure and the processing equipment of the governor speed control lever parts can be designed as shown in Table 2 . The main contents include the operation sequence, the process content, the machining equipment choice, as well as the fixtures, cutters, measuring tools and the like.

Determine the Process Size and the Cutting Parameters. Determination of the Processing Allowance and Tolerances. By looking at concise manual mechanical manufacturing process design, for the $\phi 6 \mathrm{H} 9$ hole the fine reaming allowance is $0.2 \mathrm{~mm}$ and the drill allowance is $5.8 \mathrm{~mm}$. And the machining accuracy level for each working step size is IT9 for finish ream and IT12 for drill. Then the tolerance values of each work step can be confirmed by looking up the standard tolerance value table, which is $0.030 \mathrm{~mm}$ for finish ream and $0.120 \mathrm{~mm}$ for drill. In conclusion, the processing allowance and tolerances are $\phi 6+0.03 \mathrm{~mm}$ for the finish ream and $\phi 5.8+0.12 \mathrm{~mm}$ for drill.

The Calculation of Cutting Parameter. Drilling Word Step. Firstly, choose the depth of cut. The depth of cutis is the normal distance between the un-machined surface and the machined surface. By checking the manual mechanical manufacturing process design, we take the $a_{\mathrm{p}}=5.8 \mathrm{~mm}$. Secondly, choose the cutting feed. Select the feed per revolution for each step $f=0.1 \mathrm{~mm} / \mathrm{r}$. At last, calculate the cutting speed. By looking up the table, we take the cutting speed $22 \mathrm{~m} / \mathrm{min}$, according to the material of the parts is 30 steel conditions. And the drill speed $n=1208 \mathrm{r} / \mathrm{min}$ can be calculated from the equation $n=1000 \mathrm{v} /(\pi d)$. At last we take the $n=1360 \mathrm{r} / \mathrm{min}$, referring to the range of spindle speed of Z525 vertical driller. Replacing the speed into the formula again, the actual drilling 
speed is $v=n \pi d / 1000=24.8 \mathrm{~m} / \mathrm{min}$.

Finish Ream Word Step. Choose the depth of cut. $a_{\mathrm{p}}=0.2 \mathrm{~mm}$; Choose the cutting feed. Select the feed per revolution for each step $f=0.3 \mathrm{~mm} / \mathrm{r}$.; Calculate the cutting speed. As in the above case, the actual drilling speed is $v=n \pi d / 1000=5.12 \mathrm{~m} / \mathrm{min}$.

Table 2 The manufacturing procedure and the processing equipment

\begin{tabular}{|c|c|c|c|}
\hline Number & Process name & Equipment & Tools and gauges \\
\hline I & $\begin{array}{l}\text { Rough milling both sides } \\
\text { of the horizontal and the } \\
\phi 18 \text { cylindrical ends. }\end{array}$ & $\begin{array}{l}\text { X62 horizontal milling } \\
\text { machine }\end{array}$ & $\begin{array}{l}\text { milling cutter } \\
\text { vernier caliper } \\
\text { special fixture }\end{array}$ \\
\hline II & $\begin{array}{c}\text { Rough milling } \phi 18 \\
\text { cylindrical outer surface }\end{array}$ & $\begin{array}{l}\text { X62 horizontal milling } \\
\text { machine }\end{array}$ & $\begin{array}{l}\text { milling cutter } \\
\text { vernier caliper } \\
\text { special fixture }\end{array}$ \\
\hline III & $\begin{array}{c}\text { Roughing radius of } R 6.5 \\
\text { semicircle }\end{array}$ & $\begin{array}{l}\text { X62 horizontal milling } \\
\text { machine }\end{array}$ & $\begin{array}{l}\text { milling cutter } \\
\text { vernier caliper } \\
\text { special fixture } \\
\end{array}$ \\
\hline IV & $\begin{array}{l}\text { Drill, rough reaming and } \\
\text { finish reaming the } \phi 12 \mathrm{H} 7 \\
\text { hole, chamfer }\end{array}$ & $\begin{array}{l}\text { Combination drilling } \\
\text { machine }\end{array}$ & $\begin{array}{c}\text { twistdrill } \\
\text { reamer } \\
\text { insidemicrometer } \\
\text { specialfixture }\end{array}$ \\
\hline V & $\begin{array}{l}\text { Boring the } \phi 12.5 \text { hole, } \\
\text { chamfer }\end{array}$ & Boring machine & $\begin{array}{c}\text { boring cutter } \\
\text { inside micrometer } \\
\text { special fixture } \\
\end{array}$ \\
\hline VI & $\begin{array}{l}\text { Rough milling the } \\
\text { cylinder groove }\end{array}$ & $\begin{array}{l}\text { X62 horizontal milling } \\
\text { machine }\end{array}$ & $\begin{array}{l}\text { milling cutter } \\
\text { vernier caliper } \\
\text { special fixture } \\
\end{array}$ \\
\hline VII & $\begin{array}{l}\text { Rough milling the right } \\
\text { side of the boss }\end{array}$ & $\begin{array}{l}\text { X62 horizontal milling } \\
\text { machine }\end{array}$ & $\begin{array}{l}\text { milling cutter } \\
\text { vernier caliper } \\
\text { special fixture }\end{array}$ \\
\hline VIII & $\begin{array}{c}\text { Drill and ream the double } \\
\phi 6 \mathrm{H} 9 \text { holes, chamfer }\end{array}$ & $\begin{array}{l}\text { Combination drilling } \\
\text { machine }\end{array}$ & $\begin{array}{c}\text { twist drill } \\
\text { reamer } \\
\text { inside micrometer } \\
\text { special fixture }\end{array}$ \\
\hline IX & $\begin{array}{c}\text { Drill and ream the } \phi 6 \mathrm{H} 9 \\
\text { hole, chamfer }\end{array}$ & $\begin{array}{l}\text { Combination drilling } \\
\text { machine }\end{array}$ & $\begin{array}{c}\text { twist drill } \\
\text { reamer } \\
\text { inside micrometer } \\
\text { special fixture }\end{array}$ \\
\hline $\mathrm{X}$ & Washing & Cleaning machine & \\
\hline XI & Final inspection & & $\begin{array}{c}\text { plug gauge } \\
\text { dial indicator } \\
\text { callipers } \\
\end{array}$ \\
\hline
\end{tabular}

\section{Conclusion}

The machining process planning is a kind of technology files for making the cutting process and operating procedures. Choosing a reasonable locating criterion, analyzing the technological property, drafting the process route, and selecting the reasonable manufacturing procedure and the processing equipment, not only increase the productivity and the qualified rate of the governor speed control lever, but also prolong the service life of products and help decrease the cost of production. 


\section{References}

[1] S. Wang, X. Lu, X. X. Li, W. D. Li. A systematic approach of process planning and scheduling optimization for sustainable machining [J]. Journal of Cleaner Production, 2014

[2] Li-hui Wang, An overview of function block enabled adaptive process planning for machining[J]. Journal of Manufacturing Systems, 2015, Vol.35

[3] Ren-tao Cao, Chao-shan Xiong, Three-dimensional modeling and machining process planning optimized design of the lathe cutter turntable [J].Manufacturing Automation, 2015, Vol.03

[4] XinGao, Wenping Mou, Yu Peng, An Intelligent Process Planning Method Based on Feature-based History Machining Data for Aircraft Structural Parts[J]. Procedia CIRP, 2016, Vol.56

[5] Pilai Wu, Study on Machining Process of Typical Parts[J].Mechanical Management and Development, 2017, Vol.01

[6] Jianming Zho, Machining procedure and special fixture design for connecting rod parts[J]. Modern Salt and Chemical Industry, 2016, Vol.43

[7] Yu-long Hao, Zhi-long Duan, Study on Machining Process of Typical Parts[J].Science \& Technology Vision,2014, Vol.06

[8] Qinfu Dong,JianLi,Try to Explore the Influence of Machining Procession the Machining Precision[J]. Modern Manufacturing Technology and Equipment, 2016, Vol.07 